\title{
Funding battle heats up over large array
}

Jonathan Knight, San Francisco

Astronomers around the world are gearing up to fight to secure funds for a large array telescope in the Andes that would help them study how galaxies are formed.

Such an instrument has been a top astronomy priority for years, and on 6 April research-agency representatives from Japan, North America and Europe met in Tokyo but promised only to try to reach agreement on its construction.

Funding for the Atacama Large Millimeter Array (ALMA) is not yet assured - particularly in the United States, which is supposed to pay about one third of its $\$ 660$ million construction costs.

The Bush administration's first budget proposal, issued in February, allowed no money for ALMA from the National Science Foundation (NSF), which funds groundbased astronomy in the United States.

The NSF had planned to start construction in 2002, using money it had meant to spend on the smaller Millimeter Array, a US project which was subsumed into ALMA. ALMA also absorbed Europe's Large Southern Array proposal and a Japanese project, the Large Millimeter and Submillimeter Array.

ALMA would be located on the Andean plateau in Chile, where the dry atmosphere will allow short-wavelength signals to reach the telescope. The most distant galaxies can be observed as they were when they first formed because it takes so long for their light to reach Earth. Dust around young stars blocks out most of the visible light in these galaxies, but the millimetre and submillimetre radiation shines through.

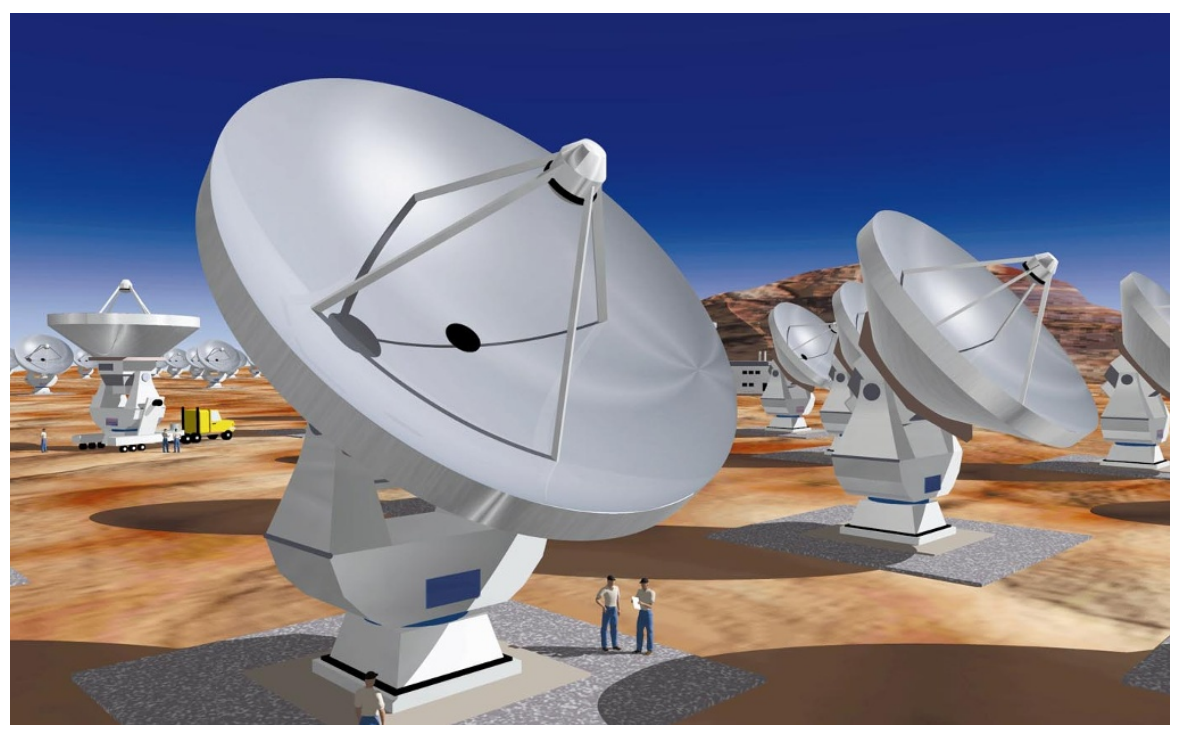

Star performer: the Atacama Large Millimeter Array would study the formation of distant galaxies.

"It means that you can make very detailed images of galaxies and stars in formation," says Bob Brown, deputy director of the National Radio Astronomy Observatory, which oversees the US contribution to ALMA.

ALMA's 64 12-metre dishes would simulate a dish of up to 14 kilometres across. Integrating the 64 signals would provide a resolution ten times better than that of the Hubble Space Telescope. As well as resolving very distant galaxies, ALMA should be able to detect planets in our own galaxy.

Funding for ALMA in 2002 is likely to be approved in Europe and Japan, but astronomers face an uphill battle in the United States. A panel of scientists has advised the
NSF that construction should proceed next year.

US researchers are preparing to take their case to Congress, which will consider the Bush proposal and develop a final 2002 budget by October. The Senate has indicated that it would like to give more money to the NSF than Bush proposed (see page 731).

Canada is expected to decide on a US\$30 million contribution later this month, says Ralph Pudritz, an astronomer at McMaster University in Hamilton, Ontario. Pudritz adds that no single country's contribution will be absolutely critical in 2002. "As long as the taps have started to turn on at some significant level, construction can begin," he claims.

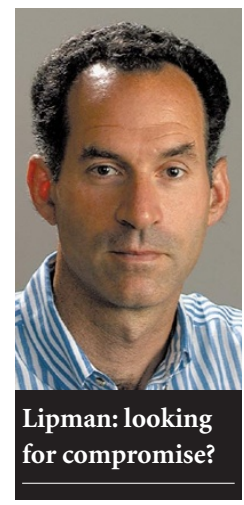

journals, including Science (see Nature 410, 502; 2001), are deciding to post free back content on their own websites, in most cases within a year.

The announcement is the latest development in the debate over how, when and at what price biomedical scientists will be able to access extensive electronic archives of published articles. Those involved in the discussion, including commercial and academic publishers, rebel scientists and librarians, are to meet next week (16-18 April) at Cold Spring Harbor Laboratory in New York state to discuss electronic publishing issues.
The meeting takes place against the backdrop of a threatened boycott by several thousand scientists, who have pledged to stop buying, publishing in or reviewing for journals that refuse to make their research articles freely available within six months.

Some publishers see the change as an acknowledgement by PMC of a failure to recruit the journals it needs to provide a near-exhaustive archive of biomedical literature. "They've lost that battle, now they're waving a white flag," says one commercial publishing executive, who declined to be identified. "They're saying they'll allow us to not deposit. Well, nobody was going to deposit anyway."

This executive says the PMC's new policy still does not guarantee journals an adequate return. "They are [still] basically trying to pin publishers down to say 'any income we make we will make in the first six months, at most a year'. That's not a model that most publishers know whether they can accept."

Catherine DeAngelis, editor of the Journal of the American Medical Association, calls the new policy "a step in the right direction" because it will allow journals to retain material on their own websites. But she bristles at the demand that journals that link to the site make back content free within a year. "I would love the whole world to get [our content] immediately. But our journal would go under if we didn't have money to run it," she said.

Other publishers say that the change could help the PMC to recruit more journals. Martha Howe, president of the American Society for Microbiology, which publishes ten journals, says that "it may well make participation easier". 